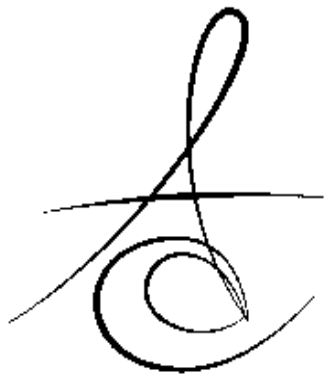

\section{ZİRKONYA ALT YAPI İLE VENEER SERAMİK ARASINDAKİ BAĞLANTI BAŞARISINI ETKİLEYEN FAKTÖRLER}

\section{THE FACTORS AFFECTING THE SUCCES OF CONNECTION BETWEEN ZIRCONIA CORES AND VENEER CERAMIC}

\author{
Dt Gökhan ÖZDEMİR** \\ Prof. Dr. Zelal SEYFIOĞLU POLAT**
}

Makale Kodu/Article code: 2489

Makale Gönderilme tarihi: 10.12 .2015

Kabul Tarihi: 15.04 .2016

öz

Günümüzde zirkonya esaslı seramiklerin kullanım alanları giderek artmıştır. Zirkonya alt yapılar oldukça dirençli yapılardır ancak zirkonya alt yapı üzerine uygulanan veneer seramiğin kırıması veya tabaka halinde alt yapıdan ayrılması problem olmaya devam etmektedir. Zirkonya ile üst yapı seramiği arasındaki bağlantı dayanıklılığ; zirkonya alt yapı üzerine uygulanan yüzey işlemleri, üst yapı seramiğinin mekanik özellikleri ve bu seramiklerin uygulama yöntemleri gibi faktörlerden etkilenmektedir. Bu derleme; zirkonya alt yapılar ve veneer seramikler arasında bağlantı başarısını etkileyen faktörler hakkında genel bilgi veren bir literatür taramasıdır.

Anahtar Kelimeler: Zirkonya, veneer seramik

\section{ABSTRACT}

Today the use of zirconia based-ceramic has increased. Zirconia cores are very resistant to crack formation, but chipping and delamination of ceramics veneers is stil a problem. The bond strength between zirconia and veneering ceramic is affected by the factors like surface treatments applied on zirconia cores, the mechanical properties of veneer ceramics and the aplication methods of ceramics. This article was a review of the literature about the factors affecting the success of connection between zirconia cores and veneering ceramics.

Key Words: Zirconia, veneer ceramic

\section{GİRİŞ}

Zirkonya seramikler, günümüzde yüksek dayanıkılık ve biyouyumluluk özellikleri sayesinde ideal dental materyal olarak kabul edilebilmektedir. Kron ve köprü protezlerinde kor materyali olarak kullanılan Zirkonya esaslı seramikler, anterior bölge ile birlikte, posterior bölgede de çok üyeli tam seramik sabit restorasyonların yapılmasına olanak sağlamaktadır. ${ }^{1-3}$ Ancak Zirkonya materyalinin yapısını oluşturan yoğun kristalin faz nedeniyle opak görünüme sahip olması ve günümüz teknolojileri ile bu seramiğe doğal dişe yakın bir translusentlik kazandırımaması dezavantajları arasındadır. Bu nedenle diğer tam seramik sistemler gibi zirkonyum oksit destekli restorasyonlar da ideal estetiğin yakalanabilmesi için uygun translüsensliğe sahip veneer seramikler ile kaplanmaktadır. ${ }^{4-6}$

Klinik çalışmalarda, zirkonya alt yapının başarı oranının $\% 97,8$ olduğu tespit edilmiştir. ${ }^{3,7}$ Zirkonya restorasyonlarda, üstyapı seramiğindeki minör kırıklar ve üstyapı seramiğinin zirkonya alt yapıdan ayrılması en sık karşılaşılan başarııızık sebebi olduğu bildirilmiştir. $^{8}$ Veneer seramiklerin bükme dayanıkllığı, zirkonya alt yapıya göre çok daha zayiftır ve bu nedenle düşük yük altında bile kor-veneer ara yüzeyinde başarısızlıklar oluşabilir. ${ }^{9}$ Uzun dönem çalışmalarda metalseramik restorasyonlarda meydana gelen delaminasyon ve/veya çatlaklar gibi klinik başarısızlıklar $\% 2,7$ ve $\% 5,5$ arasında gösterilirken, ${ }^{10,11}$ zirkonya-veneer seramikte bu oran 3 ila 5 yilın sonunda sırasıyla \%13 ve $\% 15,2$ oranlarında rapor edilmiştir. ${ }^{8,12}$

İki tabakalı tam seramik sistemlerde veneer seramiğin delaminasyonu, yani alt yapıdan tabakalar halinde ayrılması; alt yapı-üst yapı arasındaki ısısal genleşme katsayısı uyumsuzluğu, hastaya bağlı faktörler, erken temas noktalarından kaynaklanan dinamik yükler, harmonik bir oklüzyonun olmaması, yetersiz

\footnotetext{
*Adıyaman Üniversitesi Diş Hekimliği Fakültesi/Protetik Diş Tedavisi AD

**Dicle Üniversitesi Diş Hekimliği Fakültesi/Protetik Diş Tedavisi AD
} 
bağlanma kuvveti, restorasyonun uygun olmayan geometrisi, materyalin özellikleri, materyalin yorgunluğu, alt yapı desteğinin yetersiz oluşu ve seramik içi defektler gibi birçok faktöre bağlı olarak meydana gelebilir. ${ }^{13-15}$

\section{Veneer Seramiğin Uygulama Yöntemleri}

Zirkonya alt yapılar üzerine veneer seramikleri farklı yöntemlerle uygulanabilir. Bu yöntemler; alt yapılar üzerine geleneksel tabakalama tekniği, basınç altında döküm yöntemi (Presleme tekniği) ve yakın zamanda geliştirilen IPS e-max CAD tekniğidir.

\section{Tabakalama Tekniği}

Tabakalama tekniği, estetik açıdan üstün fakat dayanıklıık açısından tek başına yetersiz olan veneer seramik materyalinin daha kuvvetli bir altyapı üzerine tabakalar halinde ilave edilerek pişirilmesi esasına dayanır. ${ }^{16}$ Tabakalama tekniğinde, porselen tozu ve likidi karıştırılarak hamur kıvamına getirilir. Daha sonra karışım bir fırça yardımıyla korun üzerine kondensasyon işlemi ile uygulanır ve fırınlanır. Kondensasyon işlemi ile seramik partiküllerin arasındaki hava boşluklarının ve nemin yüzeye çıkarılması, kor ile seramik arasındaki temasın arttırıması ile buna bağlı olarak büzülmenin de azalacağı için soğuma esnasında oluşabilecek çatlaklar da önlenmiş olur. Kondensasyon işlemi vibrasyon, spatülleme veya fırçalama teknikleriyle gerçekleştirilir. ${ }^{17}$

Tabakalama tekniğinde karşılaşılan en büyük problem fırınlama sonrası yapı içerisinde \%25-35 oranında büzülmenin görülmesidir. Oluşan büzülmeyi telafi etmek için birkaç kez ilave ve pişim işlemlerinin yapılması gerekir. ${ }^{18,19,20}$ Her pişim işleminde ise seramik, ısıtılma ve soğuma işlemlerine maruz kalır ve bu durum yapı içinde mekanik özellikleri olumsuz etkileyen streslerin oluşmasına sebep olur. ${ }^{21,22}$ Zeighami ve ark. $^{22}$ yaptıkları çalışmanın sonucunda, tekrarlanan fırınlama işleminin veneer seramiğinin kristalin yapısında değişikliğe neden olduğu ve fırınlama sayısının gereksiz olarak arttırılmasından kaçınılması gerektiğini bildirmişlerdir.

\section{Presleme Tekniği}

Presleme teknolojisinin gelişmesi ile zirkonya alt yapılar için yeni nesil seramikler üretilmiştir. ${ }^{23}$ Presleme tekniği ile geliştirilen cam seramik ingotların ve yüksek dayanıklılı̆a sahip zirkonya alt yapıların avantajlarının birleştirilmesi amaçlanmıştır. ${ }^{9}$ Presleme tekniğinde, restorasyonun mum maketi hazırlanır ve revetmana alınır. Kayıp mum tekniği ile mum eliminasyonu işlemi gerçekleştirildikten sonra, önceden sinterlenmiş hazır seramik ingotlar özel fırında belli bir ISı altında yumuşatılarak basınç altında preslenir. Bu teknik ile tabakalama tekniğinde yaşanan fırınlama büzülmesi en aza indirilerek daha iyi bir marjinal uyum sağlanmış olur. ${ }^{19,20}$

Presleme tekniğinin tabakalama tekniğine göre daha kontrollü olması, veneer seramiğin daha az hatalı işlenebilmesi, dişin ideal formun oluşturulması, laboratuar ortamında tek bir pişimde gerçekleştirilmesi, seramik basınç altında şekillendirildiği için ortaya çıkan yapının daha homojen, yoğun ve küçük partiküllü olması gibi birçok avantajı vardır. ${ }^{24,25}$ Presleme tekniğinde hazırlanan mum maket, ağız ortamında prova edilebilmektedir. Ayrıca mumun seramiğe göre daha kolay işlenebilmesi hekim açısından gerekli düzenlemeler ve gerekirse ilavelerin kolaylıkla yapılmasını sağlar. Dolayısıyla ağız içinde prova esnasında harcanan zamanı ve muhtemel tekrarlanan prova randevularını azaltır. ${ }^{26}$

Presleme tekniğinin bilinen dezavantajı ise kullanılan seramiklerin tabakalama tekniğinde kullanılan seramiklere göre optik kalitelerinin dolayısıyla estetiğinin düşük olması nedeniyle ağızda estetik açıdan önemli olan bölgelerde kullanımlarının sınırlı olmasıdır. ${ }^{27}$ Ishibe ve ark.'nın ${ }^{28}$ presleme ve tabakalama tekniğiyle yüksek altın alaşım ve zirkonya alt yapılara uygulanan veneer seramiklerin makaslama bağlantı dayanımını inceledikleri çalışmanın sonucunda; zirkonya alt yapılara uygulanan tabakalama ve presleme yöntemleri arasında istatistiksel olarak anlamlı farklılık bulunmamıştır. Çalışmanın sonucunda, materyal kompozisyonlarının ve özelliklerinin, fırınlama sıcaklıklarının, soğuma derecelerinin, araştırmacının becerisinin, yüzeydeki porozitelerin ve fabrikasyon işlemlerinin alt yapı ile veneer seramiği arasındaki bağlantının dayanımını ve kalitesini etkileyebileceği bildirilmiştir. ${ }^{28}$

Tabakalama ve presleme tekniklerinin karşılaştırıldığı birçok çalışmada veneer seramiğinin yerinden çıkma veya kırılma riskinin alt yapı tasarımından kaynaklandığı belirtilmiştir. ${ }^{29,30,31}$ Aboushelib ve ark., ${ }^{27}$ zirkonya ile veneer seramikleri arasındaki bağlantı dayanımını araştırdıkları çalışmalarında, zirkonya örneklerin bir kısmına IP e.max Zirpress pres seramiği, diğer gruba liner ve IP e.max Ceram tabaka seramiği uygulamışlardır. Yapılan SEM analizinde tabaka seramiğin uygulandığı örneklerin liner yüzeylerinde hava kabarcıkları gözlenmiş ve kombine kırıklar kaydedilmiştir.

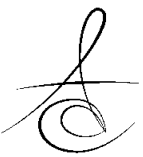


Pres seramiklerin ise yüzeyle çok daha sıkı bir yüzey teması sağladığı ve koheziv kırıkların gözlendiği belirtilmiştir.

\section{IPS e.max CAD Tekniği}

IPS e.max CAD Veneering Solutions, zirkonyum oksit alt yapılar için CAD/CAM teknolojisi ile üretilmiş veneer, lityum disilikat ve zirkonyum oksit kombinasyonlarının, diş ve implant destekli köprü restorasyonların uygulanabileceği bildirilmektedir. Veneer ve alt yapının her ikisi de dijital CAD/CAM ile üretildiği takdirde uzun köprülerin yapımındaki manuel iş yükünün önemli ölçüde azaltılabildiği belirtilmektedir. ${ }^{15,32}$ IPS e.max CAD için 4 yıllık periyodu kapsayan klinik çalışmaların olduğu, toplamda 237 restorasyonu (kronu) içeren 6 klinik çalışma ile ortalama 3 yıllık bir gözlemden sonra kırık oluşmama oranının \%97.9 olduğu bildirilmektedir. Bu değerin, metal seramiklerin ve diğer seramiklerin kırık oluşmama oranlarından daha iyi olduğu belirtilmektedir. ${ }^{32}$

Torabi ve ark., ${ }^{33}$ zirkonya alt yapılar üzerine; tabakalama, presleme ve CAD-on teknikleri ile uygulanan veneer seramiklerinin marjinal uyumunu invitro olarak değerlendirmişlerdir. Tabakalama tekniğinde $63.06 \mu \mathrm{m}$, presleme tekniğinde $50.64 \mu \mathrm{m}, \mathrm{CAD}$ on tekniğinde ise $51.50 \mu \mathrm{m}$ değerinde marjinal boşluk tespit ettikleri çalışmanın sonucunda her üç yönteminde klinik açıdan kabul edilebilir olduğunu belirtmişlerdir. ${ }^{33}$

Zirkonya Altyapı ve Veneer Seramik Arasındaki Bağlantı Başarısını Etkileyen Başlıca Faktörler

Zirkonya ile veneer porselen arasındaki bağlantı mekanizmasının henüz tam olarak anlaşımadığını belirten Fisher ve ark., ${ }^{34}$ oluşan kısıtlı bağlantının ve veneer seramiğin zayıf performansının; zirkonya ile veneer seramiği arasındaki ısısal genleşme katsayısı farkı, kimyasal bağın dayanıklıı̆ı, bağlantı yüzeyindeki defektlerin türü ve yoğunluğu, ıslanabilirlik ve mekanik kilitlenme sonucu ortaya çıkan sıkıştııııı stres miktarına bağlı olduğunu belirtilmişlerdir.

\section{Isısal Genleşme Katsayısı}

Veneer seramiğinde oluşan stresler restorasyonun başarısını belirleyen önemli bir faktördür. Alt yapı ile üst yapı arasındaki ısısal uyumsuzluk, veneer seramiğin ısısal genleşme katsayısının alt yapı seramiğinden düşük ya da yüksek olmasına bağı olarak, veneer tabakasında baskı ya da gerilim streslerinin oluşmasına neden olur. Seramikler baskı streslerine karşı dayanıklıyken, gerilim streslerine karşı dayanık- sızdır. Veneer tabakasında küçük baskı stresleri, veneer seramiğini kuvvetlendirerek, kırıma direncini arttırdığı için istenilen bir durumdur. Veneer seramiğin ısısal genleşme katsayısının alt yapıdan bir miktar düşük olması sayesinde, soğuma sırasında istenilen baskı stresleri oluşmaktadır. ${ }^{35,36}$ Veneer materyalinin ısısal genleşme katsayısı değeri, alt yapı materyalinden yüksek olduğunda ise; veneer delaminasyonu ve mikroçatlaklar gözlenebilmektedir. ${ }^{36}$

Zirkonyum oksit seramiklerin Isısal genleşme katsayıSı $\left(10.8 \times 10^{-6} \mathrm{~K}^{-1}\right)$, zirkonyum oksit altyapılar için kullanılan veneer seramiklerin termal genleşme katsayısın $\left(9.1-9.7 \times 10^{-6} \mathrm{~K}^{-1}\right)^{\prime}$ dan biraz daha büyüktür. Soğuma sırasında zirkonya hızla büzülerek veneer seramiğe sıkışıııcı kuvvet uygulamasına neden olur. Böylece metal destekli porselen sistemlerindekine benzer şekilde az miktardaki sıkışmayla daha zayıf olan veneer seramik zirkonyum oksit seramiğine bağlanır ${ }^{37,38}$ Zirkonya, diğer seramiklere göre daha düşük ısısal genleşme katsayısına sahip olduğu için, zirkonya ile aynı veya daha düşük ısısal genleşme katsayısına sahip özel üst yapı seramikleri geliştirilmiştir. Tam seramik restorasyonlarda, alt yapı ve üst yapı seramiği arasındaki ısısal genleşme katsayısı uyumsuzluğunun olabildiğince az olması, alt yapı ve üst yapı seramiği arasında oluşan bağlantı başarısını etkilemektedir. ${ }^{39}$

\section{Bağlantı Mekanizması}

Tholey ve ark., ${ }^{40}$ Y-TZP zirkonya alt yapı ile veneer seramik arasında bağlantı mekanizmasını inceledikleri çalışmalarında; homojen yapının olması ve cam fazdaki iyon alışverişinin kimyasal bağlantı oluşturabileceğini belirtmişlerdir. Ancak buna karşlık Kwon ve ark. ${ }^{41}$ sinterleme yapıldıktan önce ve sonraki zirkonya yüzeyi ile veneer seramik ara yüzeyi arasında mikropörözitelerin oluştuğunu, element difüzyonunun veya migrasyonunun olmadığını gözlemlemişlerdir. Buna dayanarak, zirkonya-veneer seramik arasındaki bağlantı mekanizmasının kimyasal değil mekanik olarak oluştuğu, ayrıca ara yüzeyde oluşan mikropörözitelerin bu bağlanmada ana faktör olabileceğini belirtmişlerdir.

\section{Geometrisi \\ Veneer Seramiği ve Restorasyonun}

Günümüze kadar yapılan çalışmaların sonucunda zirkonya alt yapılı restorasyonlarda en zayıf kısmın veneer seramiği olduğu ve veneer seramiği güçlendirilirse kırılma riskinin azaltılacağı bildirilmiştir. ISO 6872 ve 9693 standartlarına göre veneer seramiğinin bükülme direncinin minimum $50 \mathrm{MPa}$ olması gerek-

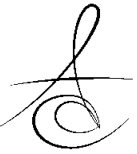


Atatürk Üniv. Diş Hek. Fak. Derg.

J Dent Fac Atatürk Uni

Cilt:26, Sayı: 2, Yıl: 2016, Sayfa: 370-376
TOPRAK GÜNDÜZ, ÖZDEMIR BURSA, POLAT mektedir. ${ }^{15}$ Zirkonya alt yapının kalınlığının üst yapı seramiğinin kalınlığına oranı, çatlak ilerlemesini ve olası başarısızlıkları belirleyen ana faktörler arasındadır. Bu tabakaların kalınlaştırılması ve üst yapı seramiğinin baskı gerilimlerine, alt yapı seramiğinin ise germe gerilimlerine maruz kalması sağlanmalıdır. Seramik alt yapı materyalinin kalınlığının arttırılması istense de, bu durum restorasyonun aşırı konturlu yapılmasına ya da dişten fazla madde kaldırımasına neden olmamalıdır. ${ }^{42}$

\section{Liner Materyalinin Kullanımı}

Liner, zirkonya alt yapı ile veneer seramik arasında alt yapının opak görüntüsünü maskelemek ve de zirkonyanın ıslanabilirliğini artırmak için ara tabaka olarak uygulanır. Zirkonya-veneer seramik bağlanma dayanımında liner uygulama dikkate alınması gereken faktörlerden biridir. Bazı materyal kombinasyonlarında kullanılan bu ek ara tabaka bağlanma dayanımını önemli derecede etkilemektedir. ${ }^{23}$

Liner materyalinin, kimyasal ve mekanik bağlanmayı artırdığını belirten çalışmalarla birlikte ${ }^{43,44}$, bağlanma dayanımını azalttığını gösteren çalışmalar da vardır. ${ }^{45,46}$ Özellikle preslenebilir veneer seramikler için kullanıldığında bağlanma kuvvetini önemli derecede zayıflattığı ve veneerin delaminasyon riskini dramatik bir şekilde arttırdığı da rapor edilmiştir. ${ }^{23,45}$ Cengiz ve ark. ${ }^{47}$ farklı yüzey işlemleri ve liner materyalinin uygulamasının bağlanma dayanımını araştırdıkları tez çalışmasına göre: liner materyalinin hem tabakalama hem presleme tekniğinde bağlanma dayanımını dramatik bir şekilde düşürdüğünü, uygulanan farklı yüzey işlemlerinin ise etki etmediğini belirtmişlerdir.

\section{Yüzey Pürüzlendirme İșlemleri}

Mekanik retansiyonun arttırılması için pürüzlendirme işlemi ile; yüzey alanı, yüzey enerjisi ve yüzey ıslatılabilirliği arttırılmış olur. ${ }^{48}$ Pürüzlendirmek için kullanılan yüzey işlemleri; alüminyum oksit ile kumlama, düşük grenli elmas döner aletler ile pürüzlendirme, asit ile pürüzlendirme, plazma sprey yöntemi ve bu metodların herhangi bir kombinasyonu uygunlanmaktadır. 2,34,39,46-48 Kumlama, tam seramik restorasyonların yüzey pürüzlülüğünü arttırmada yaygın olarak uygulanan bir yöntemdir. ${ }^{34,42,47,49}$ Kumlama yöntemi ile oksitler ve kontamine tabakalar uzaklaştırılarak mekanik bağlantı sağlayacak temiz ve pürüzlü yüzeyler elde edilir. ${ }^{50} \mathrm{Bu}$ işlem genellikle $50-250 \mu \mathrm{m}^{\prime}$ lik $\mathrm{Al}_{2} \mathrm{O}_{3}$ tozlarının 4-6 atmosfer basınçı kumlama cihazlarında püskürtülmesi esasına dayanmaktadır. ${ }^{50,51,52} \mathrm{Kim}$ ve ark. , ${ }^{2} \mathrm{Al}_{2} \mathrm{O}_{3}$ ile kumlama işleminin, liner uygulamalarına göre zirkonya alt yapı ile üst yapı seramiği arasında oluşan bağlantı dayanıklııı̆ını arttırdığını, tek başına liner uygulamasının ise bağlantı dayanımını azalttığı bildirilmişlerdir. Ancak Uludamar ve ark., ${ }^{3}$ aluminyum partiküllerinin zirkonya yüzeyine gömülme riski sebebiyle zarar verebileceğinden altyapının alüminyum ile kumlanmaması gerektiğini belirtmişlerdir. Fisher ve $a^{2}{ }^{46}$ ise farklı yüzey işlemlerinin zirkonya-veneer seramik arasındaki bağlanmaya olan etkisinin açık olmadığını belirtmişlerdir.

Özkurt ve ark. ${ }^{52}$ dört farklı zirkonya materyali ile ve iki farklı veneer seramiğinin yer aldığı çalışmalarının sonucunda bağlantı değerleri arasındaki farklılığın, veneer seramikleri ve sinterlenmiş ya da sinterlenmemiş zirkonya blokların kullanımından kaynaklandığını belirtmişlerdir. Liner materyalinin ve farklı yüzey işlemleri uygulamalarının zirkonya ve veneer seramiği arasında bağlantı değerlerini etkilemediğini vurgulamışlardır.

Seramik yüzeylerinin elmas frezlerle aşındırılması ile mekanik bağlantı sağlanır. Elmas frezler kullanıldığında diğer yöntemlere göre gözle görülebilir daha pürüzlü yüzeyler elde edilebilir. ${ }^{53}$ Kou ve ark.'$n ı n^{54}$ beş farklı seramiğin yüzey pürüzlülüğünü inceledikleri çalışmada, yüzey pürüzlülüğünün aşındırma işleminde, polisaj işleminden daha fazla olduğunu belirtmişlerdir. Benzer şekilde, zirkonyum oksit esaslı restorasyonlarda küçük grenli elmas frezlerle yapılan aşındırmalar sonucunda gelişmiş bükülme direnci elde edilirken, kalın grenli frezlerle $(150 \mu \mathrm{m}$ gren boyutuna sahip elmas frez) yapılan aşındırmalar sonucunda bükülme direncinde azalma gözlemlenmiştir. Yapılan çaıışmalar sonucunda, aşırı ısınmanın eşlik ettiği aşındırma işlemlerinde tersine faz dönüşümü meydana geldiği ve zirkonyum oksit seramiğin direncinde azalmaya neden olduğu bildirilmiştir. ${ }^{55,56}$

Zirkonyum oksit alt yapı materyaliyle üst yapı porseleni arasındaki bağlantı direncine etkilerinin araştırıldığı tez çalışması sonucunda, zirkonyum oksit seramiklere uygulanan yüzey işlemleri (asitle pürüzlendirme, kumlama, frezle aşındırma ve plazma sprey) sonucunda en fazla $\mathrm{t} \rightarrow \mathrm{m}$ faz dönüşümünün, kumlanmış örneklerde olduğu bildirilmiştir. Bununla birlikte makaslama bağlantı direnci testi değerlerine göre, kumlama işlemi sonucunda zirkonyum oksit materyalinde gözlemlenen yüksek monoklinik grenlerin bağlantı direncine etkili olmadığını belirterek, zirkonyum oksit alt yapı-üstyapı porselenleri arasındaki bağlantı direncinin artırılması için, yüzey pürüzlendirme işlemlerinin

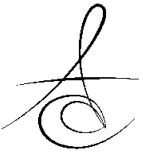


uygulanmasına gerek olmadığı belirtilmiştir. ${ }^{57}$

Kosmac ve ark., ${ }^{58} \% 4$ 'lük asidik asit solüsyonunda 16 saat bekletilen $\mathrm{Y}_{3}$ TZP seramikleri ile yaptıkları çalışma sonucunda, önemli miktarda tetragonal zirkonyumun, monoklinik zirkonyuma dönüştüğünü bildirmişlerdir. Fakat geleneksel asit uygulamalarının, zirkonyum oksit seramikleri-siman bağlantı direncinde olumlu etkisinin olmadığını belirten çok sayıda çalışma da bulunmaktadır. ${ }^{17,42,48}$

Aboushelib ve ark. ${ }^{27}$ seramik sistemleri arasında en düşük bağlantı direncinin Y-TZP alt yapılarda görüldüğünü belirtmişlerdir. Bunun sebebi olarak yüzey pürüzlendirme işlemlerinin Y-TZP seramiklerde daha zor yapılması gösterilmiştir. CAD-CAM sistemlerinde freze edilen alt yapıların yüzeyinde, kumlama yapıldığında retansiyonun daha fazla olduğu ve kumlama işleminin renkli bloklarda beyaz bloklara oranla pürüzlülüğü arttırırken çatlak oluşumunu da arttırdığı bildirilmiştir. Ayrıca Y-TZP alt yapılarda renklendirici sıvıların yüzey uygulaması yapılmamış alt yapıya uygulanması ve üst yapının preslenmesinin bağlantı direncini düşürürken, çatlak oluşumunu arttırdığını bildirmişlerdir.

Güngör ve ark., ${ }^{59}$ zirkonya alt yapılara uygulanan kumlama, elmas döner aletlerle aşındırma, aşındırma+kumlama gibi farklı yüzey işlemlerinin, yüzey pürüzlülüğü,faz dönüşümü ve veneer seramik ile biaksiyal bükülme dayanamını araştırdıkları çalışmada; farklı zirkonya alt yapıların (Kavo ve Noritake zirkonya) farklı dayanım gösterdiği, ayrıca yüzey işlemlerinin, yüzey pürüzlülüğünü arttırarak monoklinik faz dönüşümünü göreceli olarak arttırdığını belirtmişlerdir.

\section{SONUÇ}

Tam seramik alt yapı ve veneer seramiği bağlanma kuvvetinin metal-seramik bağlanma kuvvetine henüz ulaşmamış olmasından bağlanma kuvvetinin arttırılması ve klinik komplikasyonların azaltılması için çalışmaların devam etmesi gerekmektedir. Bununla birlikte, tam seramik alt yapı yüzeyine uygulanan kumlama, aşındırma ve dağlama gibi yüzey hazırlık işlemlerinin daha hassas ve kontrollü bir şekilde uygulanması, dayanıklılığı arttırılmış veneer seramiklerin geliştirilmesi ve alt yapıların uniform kalınlıkta değil, anatomik formda hazırlanması ile veneer kırılma riski azaltılabilir. Daha kesin sonuçlara varabilmek için bu konuda daha fazla in vitro ve in vivo çalışmalara ihtiyaç duyulmaktadır.

\section{KAYNAKLAR}

1- Luthardt RG, Holzhüter MS, Rudolph $H$, Herold V, Walter MH. CAD/CAM machining effects on Y-TZP zirconia. Dent Mater 2004; 20: 655-62.

2- Kim HJ, Lim HP, Park YJ, Vang MS. Effect of zirconia surface treatments on the shear bond strength of veneering ceramic. J Prosthet Dent 2011; 105: 315-22.

3- Uludamar A, Aygün Ş, Özkan YK. Zirkonya esaslı tam seramik restorasyonlar. Atatürk Üniv Diş Hek Fak Derg 2012; 5:132-41.

4- Powers JM, Wataha JC. Dental materials properties and manipulation. 9th Ed.St Louis: Mosby Elsevier, 2008:186-95.

5- White SN, Miklus VG, McLaren EA, Lang LA, Caputo AA. Flexural strength of a layered zirconia and porcelain dental all-ceramic system. J Prosthet Dent 2005; 94: 125-31.

6- Sundh A, Molın M, Sjogren G. Fracture resistance of yttrium oxide partially- stabilized zirconia allceramic bridges after veneering and mechanical fatigue testing. Dent Mater 2005; 21: 476-82.

7- Molin MK, Karlsson SL. Five-year clinical prospective evaluation of zirconia-based Denzir 3unit FPDs. Int J Prosthodont. 2008; 21:223-7.

8- Sailer I, Feher A, Filser F, Lüthy $H$, Gauckler $D$, Scharer $\mathrm{P}$, Franz Hammerle $\mathrm{CH}$. Prospective clinical study of zirconia posterior fixed partial dentures:3year follow-up. Quinressence Int. 2006; 37: 68593.

9- Guess PC, Zhang Y, Thompson VP. Effect of veneering techniques on damage and reliability of Y-TZP trilayers. Eur J Esthet Dent. 2009; 4: 26276.

10-Coornaert J, Adriaens P, De Boever J. Long-term clinical study of porcelain- fused- to- gold restorations. J Prosthet Dent. 1984; 51: 338-42.

11-Valderhaug J. A 15-year clinical evaluation of fixed prosthodontics. Acta Odontol Scand 1991; 49: 3540.

12- Raigrodski AJ, Chiche GJ, Potiket N, Hochstedler JL, Mohamed SE, Billiot S, Mercante DE. The efficacy of posterior three-unit zirconium- oxidebased ceramic fixed partial dental prostheses: a prospective clinical pilot study. J Prosthet Dent. 2006; 96: 237-44. 
13- White SN, Miklus VG, McLaren EA, Lang LA, Caputo A.A. Flexural strength of a layered zirconia and porcelain dental all-ceramic system. J Prosthet Dent. 2005 Aug; 94(2): 125-31.

14- Dejager $N$, Pallav $P$, Fellzer $A J$. The influence of design parameters on the FEA-determined stress distribution in CAD-CAM produced all-ceramic dental crowns. Dent Mater 2005; 21: 242-51.

15-Yalım BB, Türker ŞB. Klinikte zirkonya esaslı seramikler. Atatürk Üniv Diş Hek Fak Derg 2012; 5: 91-7.

16-Hsueh C, Luttrell CR, Becher PF. Analyses of multilayered dental ceramics subjected to biaxial flexure tests. Dent Mater. 2006 May; 22(5): 460-9.

17- McLean JW. The Science and Art of Dental Ceramics, Volume 1, The Nature of Dental Ceramics and their Clinical Use. Illionis. Quintessence Publishing Co Inc. 1979;34-49.

18- Claus $H$. The Structure and Microstructure of Dental Porcelain in Relationship to the Firing Conditions. Int J Prosthodont 1989; 2: 376-84.

19- Goldin EB, Boyd NW, Goldstein GR, Hittelman EL, Thompson VP. Marginal fit of leucite-glass pressable ceramic restorations and ceramicpressed-to-metal restorations. J Prosthet Dent 2005; 93: 143-7.

20- Holden JE, Goldstein GR, Hittelman EL, Clark EA. Comparison of the marginal fit of pressable ceramic to metal ceramic restorations. J Prosthodont 2009;18:645-8.

21- Isgro G, Kleverlaan CJ, Wang $H$, Feilzer AJ. The Influence of Multiple Firing on Thermal Contraction of Ceramic Materials Used for the Fabrication of Layered All-Ceramic Dental Restorations. Dent Mater 2005; 21: 557-64.

22- Zeighami S, Mahgoli $\mathrm{H}$, Farid F, Azari A The effect of multiple firings on microtensile bond strength of core-veneer zirconia-based all-ceramic restorations. J Prosthodont 2013; 22: 49-53.

23- Aboushelib MN, Kleverlaan CJ, Feilzer AJ. Microtensile bond strength of different components of core veneered all-ceramic restorations. Part II: Zirconia veneering ceramics. Dent Mater 2006; 22: 857-63.

24- El-Mowafy O, Brochu JF. Longevity and clinical performance of IPS-Empress ceramic restorations - a literature review. J Can Dent Assoc 2002; 68: 233-7.
25- Bultan Ö. Metal-pres seramik uyumunun araştırılması. İstanbul, İstanbul Üniversitesi Sağlık Bilimleri Enstitüsü, Protetik DişTedavisi Anabilim Dalı, Doktora tez, 2006.

26- Gorman CM, McDevitt WE, Hill RG. Comparison of Two Heat-Pressed All-Ceramic Dental Materials. Dent Mater 2000; 16: 389-95.

27- Aboushelib MN, Kleverlaan CJ, Feilzer AJ. Effect of zirconia type on its bond strength with different veneer ceramics. J Prosthodont 2008; 17: 401-8.

28- Ishibe $M$, Raigrodski AJ, Flinn BD, Chung $\mathrm{KH}$, Spiekerman C, Winter RR. Shear bond strengths of pressed and layered veneering ceramics to highnoble alloy and zirconia cores. J Prosthet Dent 2011; 106: 29-37.

29- Eisenburger M, Mache T, Borchers L, Stiesch M. Fracture stability of anterior zirconia crowns with different core designs and veneered using the layering or the press-over technique. Eur J Oral Sci 2011; 119: 253-7.

30- Guess PC, Bonfante EA, Silva NR, Coelho PG, Thompson VP. Effect of core design and veneering technique on damage and reliability of Y-TZP-supported crowns. Dent Mater 2013; 29: 307-16.

31- Preis V, Dowerk T, Behr M, Kolbeck C, Rosentritt $M$. Influence of cusp inclination and curvature on the in vitro failure and fracture resistance of veneered zirconia crowns. Clin Oral Investig 2014; 18: 891-900.

32- Ivoclar Vivadent ürün kataloğu: IPS e-max CAD 2013, 655940/de/2013-02-20

33-Torabi K, Vojdani M, Giti R, Taghva M, Pardis S. The effect of various veneering technigues on the marjinal fit of zirconia copings. J Adv Prosthodont 2015; 7: 233-9.

34- Fisher J, Grohmann P, Stawarczyk B. Effect of zirconia surface treatments on the shear strength of zirconia/veneering ceramic composites. Dent. Mater J. 2008; 27: 448-54.

35- Scolaro JM, Pereira JR, Do Valle AL, Bonfante G, Pegoraro LF. Comparative study of ceramic-tometal bonding. Braz Dent J 2007;18:240-3.

36- De Jager N, De Kler M, Van Der Zel JM. The influence of different core material on the FEAdetermined stress distribution in dental crowns. Dent Mater 2006; 22:234-42. Epub 2005 Aug 11.

37- Luthardt RG, Sandkuhl O, Reitz B. Zirconia-TZP and Alumina-Advanced technologies for the 
manufacturing of single crowns. Eur J Prosthodont Restor Dent 1999; 7: 113-9.

38- De Kler M. De Jager N. Meegdees M, Van Der Zel JM. Influence of thermal expansion mismatch and fatigue loading on phase changes in porcelain veneered Y-TZP zirconia discs. J. Oral Rehabil 2007; 34: 841-7.

39- Isgro G, Pallav P, Van Der Zel JM, Feilzer AJ. The influence of the veneering porcelain and different surface treatments on the biaxial flexural strength of a heat-pressed ceramic. J Prosthet Dent 2003; 90: 465-73.

40- Tholey MJ, Berthold C, Swain MV, Thiel N. XRD2 micro-diffraction analysis of the interface between Y-TZP and veneering porcelain: role of application methods. Dent Mater 2010; 26:545-52.

41- Kwon JE. Lee SH, Lim HN, Kim HS. Bonding characteristics between zirconia core and veneering porcelain. Dent Mater 2009; 25:42.

42- Conrad J, Seong WJ, Pesun IJ. Current ceramic materials and systems with clinical recommendations: A systematic review. J Prosthet Dent 2007; 98: 389-404.

43- Edward A, McLaren EA, Russel A, Giordano RA. Zirconia-Based Ceramics: Material Properties, Esthetics, and Layering Techniques of a New Veneering Porcelain, VM9. QDT. 2005; 99-111.

44- Aboushelib MN, De Jager N, Kleverlaan CJ, Feilzer AJ. Microtensile bond strength of different components of core veneered all-ceramic restorations. Dent Mater 2005; 21: 984-91.

45- Tinschert J, Natt G, Mautsch W, Augthun M, Spiekermann $H$. Fracture resistance of lithium disilicate-, alumina- and zirconia- based three- unit fixed partial dentures: a laboratory study. Int J Prosthodont 2001; 14: 231-8.

46- Fischer J, Stawarczyk B, Sailer I, Hammerle CH. Shear bond strength between veneering ceramics and ceria-stabilized zirconia/ alumina. J Prosthet Dent 2010; 103: 267-74.

47- Cengiz D. Farklı yüzey işlemlerinin zirkonya-veneer seramiklerin makaslama bağlanma dayanımına etkisinin incelenmesi. Selçuk Üniversitesi, Saglık Bilimleri Enstitüsü. Doktora tezi 2013.

48- Blatz MB, Sadan A, Kern M. Resin-ceramic bonding: A review of the literature. J Prosthet Dent 2003; 89: 268-74.

49- Kato $H$, Matsumura $H$, Atsuta M. Effect of etching and sandblasting on bond strength to sintered porcelain of unfilled resin. J Oral Rehabil 2000; 27: 103-10.

50- Nakamura S, Yoshida K, Kamada K, Atsuta M. Bonding between resin luting cement and glass infiltrated alumina-reinforced ceramics with silane coupling agent. J Oral Rehabil 2004; 31: 785-9.

51- Fischer J, Stawarczyk B. Compatibility of machined Ce-TZP/AI2O3 nanocomposite and a veneering ceramic. Dent Mater 2007; 23: 1500-5.

52- Özkurt Z, Kazazoğlu E, Ünal A. In vitro evaluation of shear bond strength of veneering ceramics to zirconia. Dent Mater J. 2010 Mar; 29(2): 138-46.

53- Derand $P$, Derand $T$. Bond strength of luting cements to zirconium oxide ceramics. Int J Prosthodont 2000; 13: 131-5.

54- Kou W, Molin M, Sjögren G. Surface roughness of five different dental ceramic core materials after grinding and polishing. J Oral Rehabil 2006; 33: 117-24.

55- Curtis AR, Wright AJ, Fleming GJ. The influence of surface modification techniques on the performance of a Y-TZP dental ceramics. J Dent 2006; 34: 195-206.

56- Kosmac T, Oblak C, Marion L. The effects of dental grinding and sandblasting on ageing and fatigue behavior of dental zirconia (Y-TZP) ceramics. J Euro Ceram Soc 2008; 28: 1085-90.

57- Evli D. Zirkonyum esaslı seramiklerin bağlantı dirençlerinin değerlendirilmesi. Ankara Üniversitesi, Sağlık Bilimleri Enstitüsü, Doktora tezi 2008.

58-Kosmac T, Oblak C, Jevnikar P, Funduk N, Marion L. Strength and reliability of surface treated Y-TZP dental ceramics. J Biomed Mater Res 2000; 53: 304-13.

59- Güngör MB, Yılmaz H, Nemli SK, Bal BT, Aydın C. Effect of surface treatments on the biaxial flexural strength, phase transformation, and surface roughness of bilayered porcelain/zirconia dental ceramics. J Prosthet Dent 2015; 113:585-95.

\section{Yazışma Adresi}

Yrd. Doç. Dr. Derya TOPRAK GÜNDÜZ

Adıyaman Üniversitesi Diş Hekimliği

Fakültesi/Protetik Diş Tedavisi

TIf: 05063571492

email: deryatoprakgunduz@gmail.com 